\title{
Adsorption of Cesium Ion on Silk Fibroin in Aqueous Solution
}

\author{
Tsukasa Sato $^{1 *}$, Tsugumi Seki ${ }^{2}$, Shino Yokoyama ${ }^{1}$ and Shinko Ito ${ }^{1}$ \\ ${ }^{1}$ National Institute of Technology, Tsuruoka College, 104 Sawada, Inooka, Tsuruoka, Yamagata 997-8511 Japan \\ ${ }^{2}$ Advanced course of National Institute of Technology, Tsuruoka College \\ *Corresponding author: E-mail: tsato@tsuruoka-nct.ac.jp
}

\begin{abstract}
The adsorption behaviors of cesium ion on silk fibroin (SF) fibers in aqueous solution were investigated for applications to purify the contaminated water by radioactive cesium ion. The ability of adsorption of cesium was smallest among the other metal ions compared. Tendency of such adsorption was explained in terms of the stability of the combination between the ions and the SF. The optimal condition for adsorption of cesium ion was searched. The thermodynamic adsorption behavior was discussed using the Langmuir and the Freundlich equilibrium adsorption models.
\end{abstract}

Key words: adsorption, silk fibroin, cesium ion, Langmuir model, Freundlich model

\section{INTRODUCTION}

The silk fibroin obtained from the silkworm, Bombyx mori, has been used as materials of a textile fabric for a long time. Nowadays, many kinds of investigations for its applications in various fields, such as surgical sutures [1], food additives [2], cosmetics [3], and drug-release materials $[4,5]$ and so on, have been extensively carried out. Applications for adsorption of metal ions from aqueous solutions have been attempted as a special interest for environmental problems. Since the biomass polymers such as silk can be biological decomposed in a nature, there is advantage in volume decreasing the wasted adsorbents compared with other adsorbents such as zeolites and activated carbons. The filament of the natural silk fiber is constituted of silk fibroin (SF) and a water-soluble protein glue, silk sericin (SS). It has been reported that the SF has the capability to adsorb some metal ions on its specific chemical structures [6-8]. The amino acid structure of the SF provides the ability to adsorb metal ions at oxygen atoms or nitrogen atoms of amide group $(\mathrm{CONH})$. In addition, the amino $\left(\mathrm{NH}_{2}\right)$ and carboxyl groups $(\mathrm{COOH})$ at the terminals of the protein macromolecule can be ionized in water at over isoelectric point $(\mathrm{pH}>3.7)$ and form ammonium $\left(\mathrm{NH}_{3}{ }^{+}\right)$and carboxylate ions $\left(\mathrm{COO}^{-}\right)$, respectively. They can be thought that the carboxylate ions also attract the metal ions. At higher $\mathrm{pH}(>5)$, the amino groups also can attract the metal ions [7]. The schematic mechanism of adsorption is shown in Figure 1. In this study, we first compared adsorption ability in some metal ions, cesium $\left(\mathrm{Cs}^{+}\right)$, palladium $\left(\mathrm{Pd}^{2+}\right)$, copper $\left(\mathrm{Cu}^{2+}\right)$, and cerium $\left(\mathrm{Ce}^{3+}\right)$ in the aqueous solutions. In particular, we focus on the details of adsorption behavior of $\mathrm{Cs}^{+}$. The adsorption of $\mathrm{Cs}^{+}$ from water have been received much attention, because purification of water polluted by radioactive $\mathrm{Cs}^{+}$induced by the accidents in nuclear power plant in Japan is urgent subject. So far, adsorption behavior of $\mathrm{Cs}^{+}$on the SF has not been reported. We attempt to make interpretations

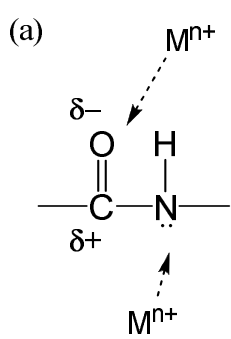

(b)

$$
\mathrm{NH}_{2}-\mathrm{SF}+\mathrm{COOH}
$$

$\mathrm{pH}>3.7$
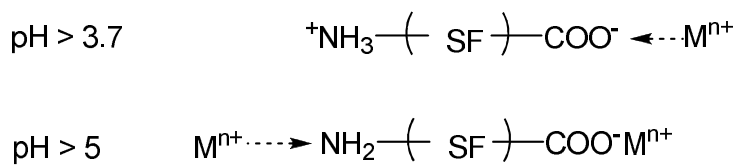

Figure 1. Adsorption mechanism of metal ions to SF. Adsorption to (a) amide structure, and (b) terminals of the SF.

for adsorption of $\mathrm{Cs}^{+}$from the viewpoints of thermodynamic models such as the Langmuir and the Freundlich models.

\section{EXPERIMENTAL PROCEDURE \\ 2.1 Preparation of silk fibroin}

The raw silk kindly supplied by MATUOKA Co., Inc. Japan was boiled with an aqueous solution of $5 \% \mathrm{Na}_{2} \mathrm{CO}_{3}$ for 1 hour to remove SS, and then to be suction filtrated separated to obtain SF. The SF obtained was washed by distilled water and dried at $45{ }^{\circ} \mathrm{C}$ for more than $24 \mathrm{hrs}$ 
under the atmosphere. The SF was immersed to the saturated $\mathrm{CaCl}_{2}$ aqueous solution. The solution of $\mathrm{CaCl}_{2}$ destroy aggregation of the SF fibers and increase surface areas of contact with solutions. Then the dialysis of SF was carried out by distilled water to remove $\mathrm{Ca}^{2+}$ and $\mathrm{Cl}^{-}$, and then was freeze dried. Thus, the fibrous SF (SF-Ca) was obtained.

\subsection{Adsorption of each metal ion}

The solutions of metal ion of $50 \mathrm{mg} / \mathrm{L}$ were prepared by diluting the original solutions of $\mathrm{CsCl}, \mathrm{PdCl}_{2}, \mathrm{Cu}\left(\mathrm{NO}_{3}\right)_{2}$, $\mathrm{Ce}\left(\mathrm{NO}_{3}\right)_{3}$ with a concentration of $1000 \mathrm{mg} / \mathrm{L}$. These solutions as an analytical grade were purchased from Kanto Chemicals Co., Inc. The $0.5 \mathrm{~g}$ of the SF-Ca prepared was added into $50 \mathrm{ml}$ of the solution and then added $30 \mathrm{~mL}$ of the buffer solution. The buffer solution was prepared by mixing the $5 \mathrm{~g}$ of $0.1 \mathrm{M}$ solution of acetic acid and $40.8 \mathrm{~g}$ of $0.6 \mathrm{M}$ solution of sodium acetic acid. The value of $\mathrm{pH}$ was controlled at 6.9. The adsorption experiments were carried out under shaking for $8 \mathrm{hrs}$ in the water bath controlled at $40{ }^{\circ} \mathrm{C}$ [6-8]. After that, SF was removed from the solution by filtration. The concentrations of the ions of $\mathrm{Pd}^{2+}, \mathrm{Cu}^{2+}$ and $\mathrm{Ce}^{3+}$ were measured by ICP analysis (Inductively Coupled Plasma, Hitachi High-technologies SPS3500DD) and the $\mathrm{Cs}^{+}$was AAS analysis (Atomic Absorption Spectrometry, Hitachi High-technologies Z-5010). Each adsorption experiments were carried out at least three times and the average values of the concentrations were determined. The removal efficiency can be calculated according to the following equation:

$$
R E[\%]=\frac{C_{i}-C_{f}}{C_{i}}
$$

where $R E$ is the removal efficiency of metal ions, $C_{i}$ and $C_{f}$ are the initial and the final concentrations of metal ions $(\mathrm{mg} / \mathrm{L})$, respectively. The amount of ions adsorbed on 1 $\mathrm{g}$ of the SF was calculated according to the following equation:

$$
q_{e}[m g / g]=\frac{\left(C_{i}-C_{f}\right) V}{m}
$$

where $q_{e}$ is the adsorption capacity, $V$ is the volume of the solution (L) and $m$ is the weight of the SF (g).

\subsection{Optimization of adsorption conditions of $\mathrm{Cs}^{+}$}

(a) Effects of adsorption disturbance by the other ions In order to clarify the effects of adsorption disturbance by the $\mathrm{Ca}^{2+}$ from $\mathrm{CaCl}_{2}$, the $\mathrm{SF}$ without immersion in $\mathrm{CaCl}_{2}$ (SF-n) was used in adsorption experiments. In addition, to confirm the disturbance by $\mathrm{Na}^{+}$from the buffer solution, the $\mathrm{CsCl}$ solution without addition of the buffer solution was employed in the experiments.

(b) Effects of contact time and initial concentration

The values of RE for the SF-n at the various contact times from 3 to $480 \mathrm{~min}$ were obtained under initial concentration of $\mathrm{CsCl}$ fixed to $10 \mathrm{mg} / \mathrm{L}$. Next, initial concentrations were changed from 5 to $100 \mathrm{mg} / \mathrm{L}$ for up to 120 min of contact time.

\subsection{Adsorption isotherm of $\mathrm{Cs}^{+}$}

In order to obtain the adsorption isotherm of $\mathrm{Cs}^{+}$for the SF-n, the $q_{e}$ at various $c_{\mathrm{e}}$, equilibrium concentration of $\mathrm{Cs}^{+}$
(mg/L), at $40{ }^{\circ} \mathrm{C}$ for $120 \mathrm{~min}$ were obtained.

\section{RESULTS AND DISCUSSIONS \\ 3.1 Removal efficiency for each metal ion}

The results of adsorption experiments were shown in Figure 2. The value for $\mathrm{Pd}^{2+}$ was the highest among the ions employed. While for the $\mathrm{Cs}^{+}$was $4 \%, i . e ., \mathrm{Cs}^{+}$ hardly adsorbs on the silk fibroin. The tendency of removal efficiency was in the order of $\mathrm{Pd}^{2+} \gg \mathrm{Cu}^{2+}>$ $\mathrm{Ce}^{3+}>\mathrm{Cs}^{+}$. Results of removal efficiency were considered from the viewpoints of ionic radius, charge number of ions, pair anion, and the HSAB (hard and soft acids and bases) rules. The favorite situations for adsorption are small size of positive ion, large number of electric charge, and small size of pair anion under suiting the $\mathrm{HSAB}$ rule. The ionic radius of $\mathrm{Cs}^{+}, \mathrm{Pd}^{2+}, \mathrm{Cu}^{2+}$ and $\mathrm{Ce}^{3+}$ were $1.81,1.00,0.87$ and $1.15 \AA$, respectively. The pair anions probably accompany around the metal ion and may play a role of spatial hindrance in adsorption. The $\mathrm{HSAB}$ rule has been established as a semi-empirically rule to predict the affinity about the metal ions (Lewis acid) to the ligand (Lewis base) [9]. The hard acid and base refer to what have small polarizability. On the other hand the soft acid and base large polarizability. The hard acids exhibit affinity to the hard bases, and the soft acids to the soft bases. $\mathrm{Cs}^{+}$and $\mathrm{Pd}^{2+}$ belong to soft acid, and $\mathrm{Cu}^{2+}$ and $\mathrm{Ce}^{3+}$ are middle and hard acid, respectively. Amino group $\left(\mathrm{NH}_{2}\right)$, and carboxylate ion $\left(\mathrm{COO}^{-}\right)$at the molecular terminals are the hard bases. These accomplish great influence in adsorption [6]. The structure of $\mathrm{C}=\mathrm{O}$ and $\mathrm{NH}$ at amide group are soft and hard bases, respectively. It should be mentioned that the contribution of the amide groups on adsorption might be restrictive, because most of amide groups associate each other by hydrogen bonds and form $\beta$-sheet structure in fibers. It can be understood that the lowest tendency of adsorption for $\mathrm{Cs}^{+}$is due to large of cation size, the charge number $(+1)$, and the HSAB rule. On the other hand, the reasons for the highest adsorption tendency of $\mathrm{Pd}^{2+}$ are the charge number, sizes of cation and the pair anion $\left(\mathrm{Cl}^{-}\right)$and $\mathrm{C}=\mathrm{O}$, although the combination of $\mathrm{Pd}^{2+}$ with $\mathrm{COO}^{-}, \mathrm{NH}_{2}$ and $\mathrm{NH}$ are not in agreement with the HSAB rule. Lower results for $\mathrm{Cu}^{2+}$ and $\mathrm{Ce}^{3+}$ may be attributed to large size of pair anion $\left(\mathrm{NO}_{3}{ }^{-}\right)$.

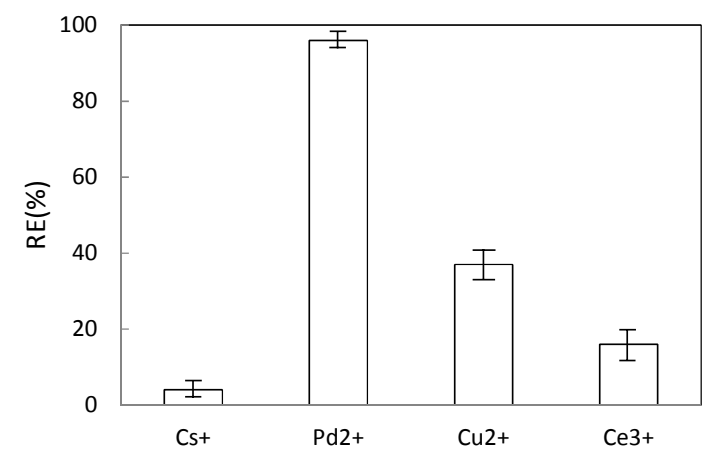

Figure 2. Results of removal efficiency of each metal ion by using the SF-Ca.

\subsection{Effect of adsorption disturbance by $\mathrm{Ca}^{2+}$ and $\mathrm{Na}^{+}$}

In Figure 3 (a) and (b), three types of SF, i. e., the raw silk fiber (coated with SS), the SF-Ca and SF-n were 
compared. As shown in (a), the results demonstrated that addition of the buffer solution was not effective for $\mathrm{Cs}^{+}$ adsorption. However, Figure 3 (b) showed that certain improvement of adsorption was observed at no buffer solution system. In particular, for the SF-n the value for $\mathrm{RE}$ reached about $40 \%$. The value of $\mathrm{pH}$ for $\mathrm{CsCl}$ solution of $50 \mathrm{ppm}$ was 7.6, which satisfied the conditions of ionizations of $\mathrm{COO}^{-}$and $\mathrm{NH}_{2}$. Changes of the values of $\mathrm{pH}$ were not recognized through the experiments. As shown in Figure 2, the adsorption of $\mathrm{Pd}^{2+}$ was not disturbed by $\mathrm{Ca}^{2+}$ and $\mathrm{Na}^{+}$. This may be attributed to that $\mathrm{Pd}^{2+}$ ion can exchange with $\mathrm{Ca}^{2+}$ and $\mathrm{Na}^{+}$since the order of ionization tendency is $\mathrm{Cs}^{+}>\mathrm{Ca}^{2+}>\mathrm{Na}^{+}>\mathrm{Cu}^{2+}>\mathrm{Pd}^{2+}>$ $\mathrm{Ce}^{3+}$. Thereafter, the adsorption experiments employed the solution without buffer solution and the SF-n.
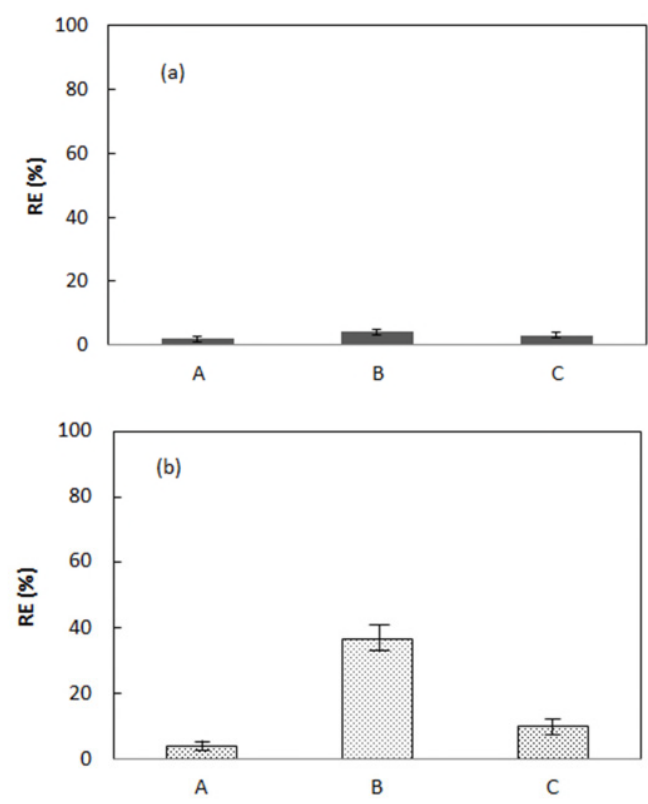

Figure 3. Influence of the state of adsorbents on removal efficiency. (a) with buffer solution, (b) without buffer solution. A: raw silk, B: SF-n, C: SF-Ca.

\subsection{Effects of contact time and initial concentration}

First, effect of contact time on the adsorption efficiency was discussed. As shown in Figure 4, the RE reached about $65 \%$ at $3 \mathrm{~min}$, which implies the adsorption proceeds rapidly at an early stage. After that the RE value somewhat decreased, which implies the occurrence of desorption. This phenomenon is based on the adsorption equilibrium. From above result, we assumed that the equilibrium is realized for contact time of $120 \mathrm{~min}$ Effect of initial concentration of $\mathrm{Cs}^{+}$on adsorption was shown in Figure 5. From the figure maximum of RE was also attained in $3 \mathrm{~min}$ except for the initial concentration of $100 \mathrm{mg} / \mathrm{L}$.

\subsection{Adsorption isotherm of $\mathrm{Cs}^{+}$}

In this study two of the most commonly used isotherm equations were employed, namely, the Langmuir type [10] and the Freundlich type [11] of equilibrium isotherms. The Langmuir equation, initially derived from kinetic considerations, was based on the assumption that there are energetically equivalent numbers of sorption sites on the

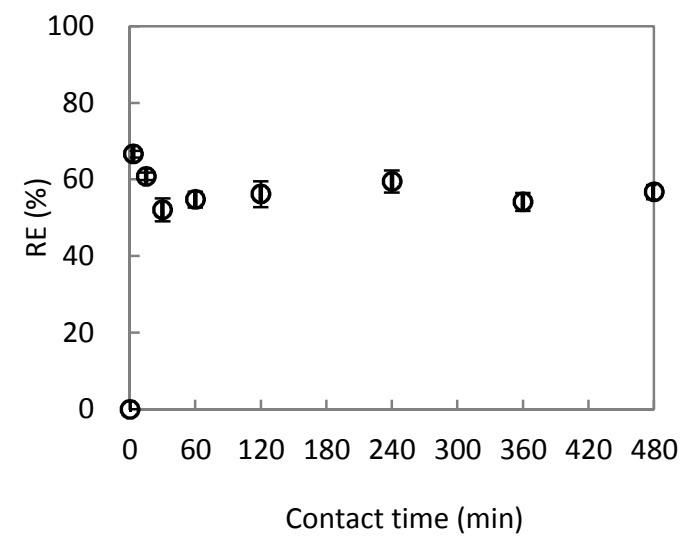

Figure 4. Effect of time on the removal efficiency for cesium ions $(\mathrm{N}=3)$ using the SF-n. The initial concentration was $10 \mathrm{mg} / \mathrm{L}$.

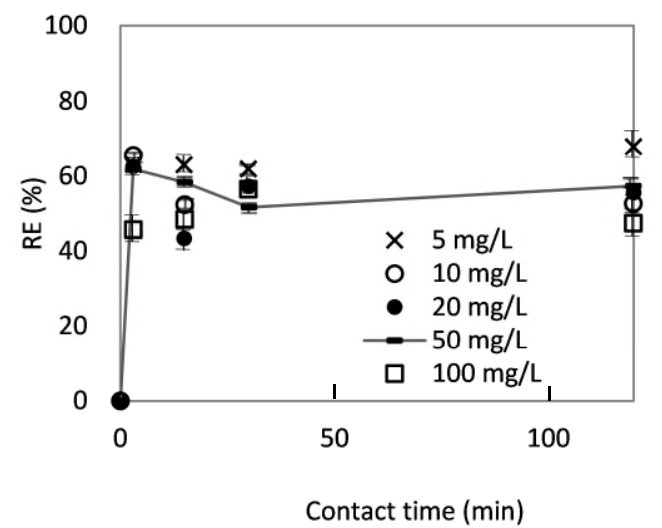

Figure 5. Effect of initial concentration on removal efficiency for cesium ions using the SF-n.

sorbent surface. The binding of adsorbates to the sorption sites can be classified either chemical or physical, but it must be sufficiently effective to prevent displacement of the adsorbates on neighboring sites. Figure 6 shows the isothermal adsorption curve of cesium ion to the SF As shown in the figure, the value of $q_{\mathrm{e}}$ monotonically increases with $C_{\mathrm{e}}$.

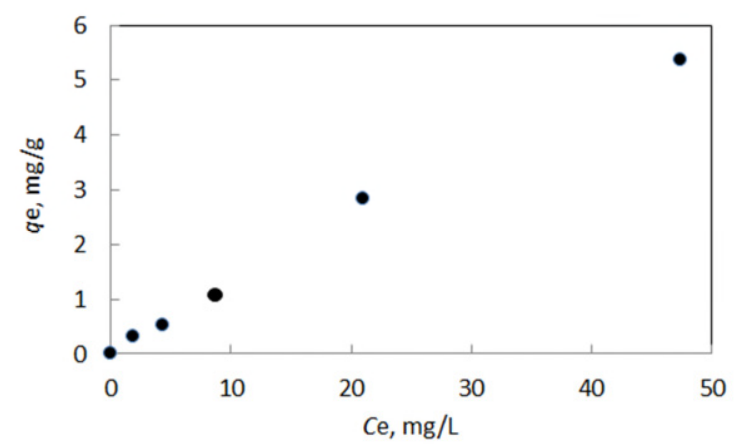

Figure 6. Adsorption isotherm of $\mathrm{Cs}^{+}$for the SF-n. 
The equation for the Langmuir model as follows:

$$
\frac{q_{e}}{q_{m}}=\frac{K_{L} c_{e}}{1+K_{L} c_{e}}
$$

Where $q_{m}$ and $K_{L}$ are corresponding to the maximum adsorption capacity of ions $(\mathrm{mg} / \mathrm{g})$ under monolayer sorption and the Langmuir constant $(\mathrm{L} / \mathrm{mg})$, respectively. $K_{L}$ means the ratio of rate constants of adsorption to desorption. Equation 4 was derived as follows:

$$
\frac{1}{q_{e}}=\frac{1}{K_{L} q_{m} c_{e}}+\frac{1}{q_{m}}
$$

If the experimental data is applied to the equation as single straight line, the value for $q_{\mathrm{m}}$ can be derived from the intercept of the plot. The value of $K_{\mathrm{L}}$ was calculated from the slope of the plot. However, Figure 7 shows that the plots would be expressed by combination of two straight lines. This suggests that the kinds of adsorption sites might be extended such as $\mathrm{NH}_{2}, \mathrm{C}=\mathrm{O}, \mathrm{NH}$, as well as $\mathrm{COO}^{-}$. Such situation was realized as the $\mathrm{pH}$ become larger than the isoelectric point of the SF. The value of $\mathrm{pH}$ was 7.6 in this system, which was applicable to such situation. It would be suggested that the occasion for repulsion between metal ions on adsorption sites increases as the adsorption sites were extended at $\mathrm{pH}$ more than the isoelectric point [6]. In another suggestion, it is expected that adsorption has taken place at the sites with large of binding energy in low concentration. This implies that the energy of adsorption changes with adsorption sites like $\mathrm{COO}^{-}, \mathrm{NH}_{2}, \mathrm{C}=\mathrm{O}$, and $\mathrm{NH}$.

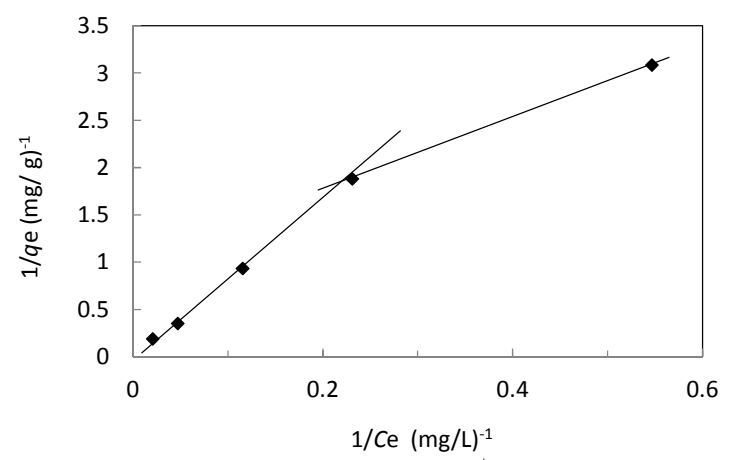

Figure 7. Adsorption isotherm of $\mathrm{Cs}^{+}$for the SF-n using the Langmuir model.

On the other hand, the Freundlich model is an empirical equation which can express the heterogeneous mixture and is expressed as follows:

$$
q_{e}=K_{f} C_{e}^{1 / n}
$$

where $K_{f}$ is a constant related to the adsorption capacity and the energy of adsorption, and $n$ is an empirical parameter related to the adsorption intensity. The following equation can be formulated as

$$
\log q_{e}=\log K_{f}+\left(\frac{1}{n}\right) \log c_{e}
$$

Figure 8 shows the plots for $\log C_{\mathrm{e}}$ vs. $\log q_{\mathrm{e}} . \quad K_{\mathrm{f}}$ can be determined from the intercept of the plot and $n$ from the

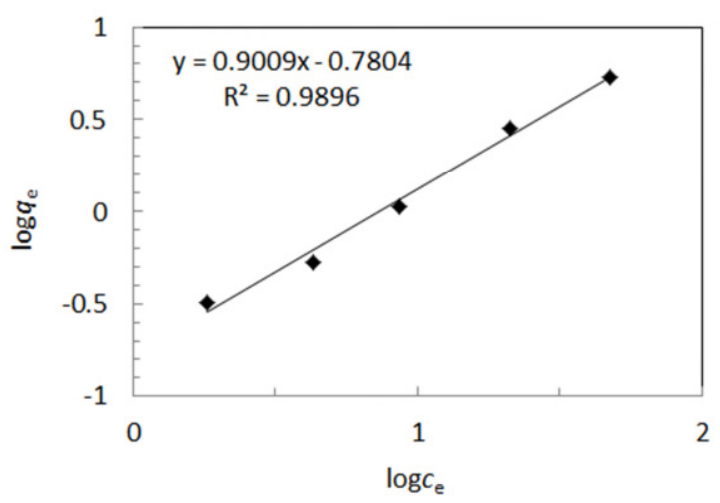

Figure 8. Adsorption isotherm of $\mathrm{Cs}^{+}$for the SF-n using the Freundlich model.

slope of the plot. As shown in the figure, the experimental data can fit linearity implying applicable to the Freundlich model. The values of $K_{\mathrm{f}}$ and $n$ are 0.166 and 1.11, respectively, and correlation coefficient $\left(r^{2}\right)$ was 0.9896. The Freundlich parameters were compared with those of reported using the other adsorbents, e. $g$., $\mathrm{Ni} /$ hexacyanoferrate-sericite $\left(K_{\mathrm{f}}=6.125 \mathrm{mg} / \mathrm{L}, n=2.54, r^{2}\right.$ $=0.991)$ [12], and prussian blue $\left(K_{\mathrm{f}}=70.4, n=2.63, r^{2}=\right.$ 0.9351) [13]. From the above comparison, the adsorption capacity and energy for $\mathrm{Cs}^{+}$towards the SF are resulted to be small.

\section{SUMMARY}

The removal efficiency of metal ions $\mathrm{Cs}^{+}$compared with $\mathrm{Pd}^{2+}, \mathrm{Cu}^{2+}$, and $\mathrm{Ce}^{3+}$ by adsorbing to the SF fibres were investigated. The efficiency for $\mathrm{Cs}^{+}$was lowest in those ions. These behaviour were explained by means of ionic radius, charge number of ions, pair anions, and HSAB rule. It was found that adsorption of $\mathrm{Cs}^{+}$was improved by avoiding $\mathrm{Na}^{+}$and $\mathrm{Ca}^{2+}$, which play a role of disturbance. The adsorption of $\mathrm{Cs}^{+}$to the SF was suggested that existence of multiple adsorption site on the SF structure.

\section{REFERENCES}

[1] N. Minoura, M. Tsukata and M. Nagura, Biomaterials, 11, 430 (1990).

[2] T. Asakura, Bioindustry, 4, 878 (1987).

[3] K. Chen, K. Iura, R. Takano and K. Hirabayashi, J. Sericult Sci Jpn, 62, 56 (1992).

[4] M. Tsukada, G. Freddi, N. Minoura and G. Allara, J. Applie. Polym. Sci, 54, 507 (1994).

[5] S. Min, T. Nakamura, A. Teramoto and K. Abe, SEN-I GAKKAISHI, 54(5), 74 (1998).

[6] F. Shimidzu, K. Jyoko, I. Sakaguchi and T. Iijima, SEN-I GAKKAISHI, 32, (4), 166 (1976).

[7] F. Shimidzu and I. Sakaguchi, SEN-I GAKKAISHI, 35(8), 352 (1979).

[8] F. Shimidzu and I. Sakaguchi, SEN-I GAKKAISHI, 36(3), 127 (1980).

[9] R. G. Pearson, J. Am. Chem. Soc. 85(22), 3533 (1963).

[10] I. Langmuir, J. Am. Chem. Soc., 40, 1361 (1918).

[11] U. Freundlich, Z. Phys. Chem., 57A, 385 (1906).

[12] C. Jeon, J. Ind. and Eng. Chem., 40, 93 (2016).

[13] A. A. Kadam, J. Jang, D. S. Lee, Biores. Tech, 216, 391 (2016).

(Received May 28, 2016; Accepted January 24, 2017; Published Online April 1, 2017) 